Cad.Est.Ling., Campinas, (44):265-282, Jan./Jun. 2003

\title{
GÊNERO, MÍDIA E RECEPÇÃO: SOBRE AS NARRATIVAS TELEVISIVAS E SEUS ESPECTADORES
}

\author{
ANNA CHRISTINA BENTES \\ INGEDORE G. VILLAÇA KOCH \\ CÁSSIA MICHELA ALVES NOGUEIRA* \\ (UNICAMP)
}

\begin{abstract}
The main objective of this article is to describe some of the ways certain individuals belonging to an specific social group exibit their knowledge about the themes, composicional structure and functioning of a mass media genre: Brazilian soap operas.
\end{abstract}

\section{INTRODUÇÃO}

Falar sobre os gêneros do discurso no interior do campo dos estudos sobre texto/discurso hoje significa, invariavelmente, procurar descrever e analisar os aspectos discursivos, textuais e/ou estruturais dos processos que constituem as diversas práticas comunicativas nas quais os gêneros são produzidos. Neste artigo, pretendemos, no entanto, olhar mais detalhadamente a "outra face"1 de uma determinada prática comunicativa, a saber: a recepção da telenovela brasileira. Apesar de ser considerada importante por todos os estudiosos, esta "outra face" é muito pouco abordada nas análises de gênero e ainda há muitas questões em aberto, principalmente sobre o(s) papel(éis) que desempenha na própria constituição dos gêneros e na qualidade das

* A autora é aluna do Curso de Graduação em Letras do Instituto de Estudos da Linguagem da Universidade Estadual de Campinas e desenvolveu pesquisa de Iniciação Científica financiada pelo CNPq sob orientação da Prof ${ }^{\mathrm{a}}$ Dra. Anna Christina Bentes.

${ }^{1}$ Os trabalhos sobre recepção de gênero com base em uma perspectiva enunciativo-discursiva são ainda escassos. O trabalho de Gomes-Santos (2003), por exemplo, embora não seja um trabalho de recepção propriamente dito, trata de analisar os modos de relação dialógica que escreventes-alunos estabelecem com a linguagem no evento escolar de produção escrita "recontando histórias". Um estudo de recepção que se encontra em desenvolvimento é o de Rio (2003), financiado pela FAPESP e intitulado "Processos de recepção de narrativas midiáticas: um estudo sociolingüístico da recepção do programa "Brava gente",, desenvolvido no Instituto de Estudos da Linguagem, sob a orientação da Profa. Dra. Anna Christina Bentes. No campo dos estudos da comunicação, já há uma série de trabalhos que deslocam o olhar para a recepção dos produtos midiáticos. A esse respeito, ver Jacks (1996), Romano (1996), Ronsini (1996), Rondelli (1998), Hamburger (1998), Costa (1999) e Andrade (2002). 
relações entre os locutores e os interlocutores que pertencem a uma determinada comunidade discursiva no interior da qual os gêneros são produzidos.

Por várias razões, não é uma tarefa fácil abordar a recepção televisiva. Em primeiro lugar, apesar de a televisão ser considerada o meio de comunicação hegemônico $^{2}$ a partir da segunda metade do século XX, pode-se dizer que, durante muito tempo, as análises voltaram-se mais "para a estrutura genérica do meio, entendida como tecnologia de difusão, empreendimento mercadológico, sistema de controle político-social, sustentáculo do regime econômico, máquina de moldar o imaginário, e assim por diante" (Machado, 1998:09). Além disso, para este autor, "a grande maioria das publicações não examina um único programa de televisão nem uma única experiência de televisão" (Machado, 1998:09).

Martín-Barbero (1987/2003) afirma que houve duas etapas na formação do paradigma hegemônico para a análise da comunicação na América Latina: uma que ele denomina ideologista, em função do fato de a pesquisa concentrar-se no objetivo de descobrir e denunciar quais "as estratégias mediantesas quais a ideologia dominante penetra o processo de comunicação"; a segunda etapa é denominada cientificista e construída com base na teoria da informação (teoria esta elaborada no interior dos campos da matemática e da engenharia); nesta segunda etapa, concebe-se a comunicação como "transmissão de informação" e tem-se como principal objetivo precisar os conceitos e delimitar metodologias, procedimentos estes considerados necessários para as análises dos meios de comunicação, "tudo com o aval das matemáticas e o prestígio da cibernética, capazes de oferecer modelos até para a estética" (Martín-Barbero, 2003:292). Ainda segundo o autor, a pressuposição que une os dois modelos, o semiótico, que corresponde à primeira etapa, e o informacional, que corresponde à segunda etapa, é uma "economia" que supõe que as duas instâncias do circuito - emissor e receptor - situam-se no mesmo plano e que a mensagem circula entre instâncias homólogas. Além disso, o autor afirma ainda que o paradigma hegemônico de análise da comunicação sustentado pelos dois modelos acima mencionados têm como pressuposto também a fragmentação do processo de comunicação, fundamentalmente porque o reduz a uma mera transmissão de informação. Isto converte em "verdade metodológica a separação da análise da

2 “A partir dos anos 1960, a cultura popular urbana passa a ser tomada por uma indústria cultural cujo raio de influência se torna cada vez mais abrangente, transpondo modelos em larga medida buscados nos mercado transnacional. A proposta cultural se torna sedução tecnológica e incitação ao consumo, homogeneização dos estilos de vida desejáveis, banimento do nacionalismo para o 'limbo anterior ao desenvolvimento tecnológico' e incorporação dos antigos conteúdos sociais, culturais e religiosos à cultura do espetáculo (...). E no centro da nova dinâmica cutural, no papel de grande interlocutor, estará a televisão. Descaradamente norte-americana e erigida em critério de uma única modernização para todo o país, a televisão decide o que é atual e o que é anacrônico, tanto no campo dos utensílios como no das falas" (Martín-Barbero, 1987/2003:280). Ainda para o autor, a hegemonia da televisão realiza-se na "unificação da demanda", ou seja, na "tendência à constituição do um só público, no qual sejam reabsorvidas as diferenças", (...) "exibindo-as livres de tudo aquilo que as impregna de conflitividade”. "(...) Nenhum outro meio de comunicação tinha permitido o acesso a tanta variedade de experiências humanas, de países, de povos, de situações. Mas também nenhum outro jamais as controlou de tal modo que em vez de implodir com o etnocentrismo, terminasse por reforçá-lo" (op.cit.:261-262). 
mensagem - seja ela uma análise de conteúdo ou de expressão - da análise da recepção, concebida simples ou sofisticadamente como indagação acerca dos efeitos ou da reação"(op. cit.:293).

No entanto, nos últimos anos, o autor afirma que começa a se formar um outro projeto para as ciências humanas, incluídos aí os estudos da comunicação, projeto este profundamente relacionado com a redescoberta do popular ${ }^{3}$ e, em decorrência disso, com a "convergência do novo sentido adquirido pelos processos de transnacionalização com a nova concepção do político 4 ", o que faz emergir na América Latina uma valorização profundamente nova do cultural. Esta valorização, ainda segundo o autor, “assinala a percepção de dimensões inéditas do conflito social, a formação de novos sujeitos - regionais, religiosos, sexuais, geracionais - e formas de rebeldia e resistência" (op.cit.:297).

Pensar as práticas comunicativas, principalmente a recepção/o consumo de "formas simbólicas mediadas" (Thompson, 1995/2002:41) a partir de uma perspectiva cultural, é colocar no centro da discussão os "atos de leitura" praticados pelo telespectador. É neste sentido que se faz importante apresentar, após este breve histórico sobre as mudanças ocorridas nos direcionamentos teóricos e metodológicos no interior do campo dos estudos da comunicação, ainda nesta introdução, a noção que está na base das reflexões de autores como Certeau e Canclini: a de consumo cultural.

Para Canclini (1997), por exemplo, a articulação entre as formas de consumo cultural e as práticas de cidadania ${ }^{5}$ podem ser comprovadas por estudos ${ }^{6}$ empíricos desenvolvidos pelo autor e por um conjunto de pesquisadores na Cidade do México e em outras capitais da América Latina. A noção de consumo é de extrema importância para este trabalho, já que reconhecemos que a telenovela é um produto da indústria cultural, produto este regido por uma racionalidade econômica, compreendido como "um lugar em que se completa o processo iniciado com a geração de produtos, onde se realiza a expansão do capital e se reproduz a força de trabalho" (Canclini, 1997:53).

${ }^{3}$ Martín-Barbero explica a redescoberta do popular como uma "revalorização das articulações e mediações da sociedade civil, sentido social dos conflitos para além de sua formulação e síntese política, reconhecimento de experiências coletivas não enquadradas nas formas partidárias" (op.cit::296).

4 "A uma concepção substancialista das classes sociais, como entidades que repousam sobre si próprias, corresponde uma visão do conflito social como manifestação dos atributos dos atores. (...) Mesmo assim, as relações de poder, tal qual configuradas em cada formação social, não são mera expressão de atributos, e sim produto de conflitos concretos, batalhas travadas no campo econômico e no terreno do simbólico. (...) A questão de fundo é que não existe uma 'solução objetiva' para as contradições da sociedade capitalista. O desenvolvimento não é orientado para soluções objetivas. É preciso, portanto, elaborar e decidir continuamente os objetivos da sociedade. Isto é fazer política" (op.cit.:296).

${ }^{5}$ Segundo Canclini (1997), a vinculação do consumo com a cidadania somente é possível quando se deixa de considerar o comportamento dos consumidores como predominantemente "irracional" ou quando nos permitimos ver os cidadãos atuando com base em princípios outros que não o da racionalidade ideológica. Assim, "ser cidadão não tem a ver apenas com os direitos reconhecidos pelos aparelhos estatais para os que nasceram em um território, mas também com as práticas sociais e culturais que dão sentido de pertencimento, e fazem com que se sintam diferentes os que possuem uma mesma língua, formas semelhantes de organização e de satisfação das necessidades" (op.cit.:22).

${ }^{6}$ As referências aos estudos coordenados e desenvolvidos pelo próprio autor podem ser encontradas na obra Consumidores e cidadãos (1997). 
No entanto, segundo o autor, esta racionalidade não é a única que modela o consumo. Para ele, uma teoria mais complexa sobre a interação entre produtores e consumidores revela que no consumo é possível também observar uma racionalidade sociopolítica interativa, já que é neste lugar, o consumo, que "os conflitos entre classes, originados pela desigual participação na estrutura produtiva, ganham continuidade através da distribuição e apropriação dos bens" (Castells,1974 apud Canclini,1997:54) Mas há ainda uma terceira racionalidade apontada por Canclini que é a que mais nos interessa aqui: aquela que mostra o consumo como um lugar de diferenciação entre as classes e os grupos, o que nos obriga a observar os aspectos simbólicos e estéticos da racionalidade consumidora. E é justamente em função das diversas formas de apropriação e elaboração, por parte dos sujeitos, dos conteúdos simbólicos produzidos na/pela mídia televisiva que as diferenciações entre as classes e os grupos são produzidas. Voltaremos a este tópico mais adiante.

As posições teóricas mobilizadas até aqui revelam as maneiras pelas quais é possível deslocar, no interior dos estudos da comunicação, o lugar a partir do qual as perguntas são formuladas. Assim, os analistas, embora continuem a questionar as mesmas coisas, a saber, dominação, produção, trabalho, elegem agora como locus privilegiado de investigação não mais os "meios", mas as "mediações" (MartinBarbero, 2003). Na próxima seção, tentaremos descrever brevemente alguns dos "lugares" (que o autor concebe como "mediações") que delimitam e configuram a recepção da telenovela por parte de um determinado grupo social.

Este artigo tem como principal objetivo descrever algumas formas de recepção da telenovela brasileira a partir da observação de grupos familiares durante a prática desta atividade cotidiana ${ }^{8}$. Sendo assim, procuraremos compreender, aproximando as noções de uso e de consumo, os recursos que permitem ao telespectador produzir ou "fabricar", no sentido de Certeau (1990/1994:40), "uma bricolagem com e na economia cultural dominante, usando inúmeras e infinitesimais metamorfoses da lei, segundo seus interesses próprios e suas próprias regras. Desta atividade de formigas, é mister descobrir os procedimentos, as bases, os efeitos, as possibilidades".

Assim, a recepção de um determinado gênero é concebida neste trabalho considerando as lógicas dos usos nos sentidos apresentados acima. Em outras palavras, a recepção dos gêneros é compreendida da seguinte forma: situada no interior dos conflitos articulados pela cultura, da complexa tessitura resultante de muitos embricamentos que a constituem, do modo como a hegemonia cultural trabalha no

${ }^{7}$ Sobre este conceito, o autor propõe que "em vez de fazer a pesquisa partir das lógicas da produção e recepção para depois procurar suas relações de imbricação e enfrentamento, propomos partir das mediações, isto é, dos lugares dos quais provêm as construções que delimitam e configuram a materialidade social e a expressividade cultural da televisão" (Martín-Barbero, 2003:304).

8 Tanto Martín-Barbero (1987/2003) como Thompson (1995/2002) chamam a atenção para a cotidianidade das práticas de consumos das produções simbólicas. Por exemplo, para o segundo autor, apesar de muitos estudos procurarem compreender a natureza e o papel dos receptores dos produtos das indústrias culturais, eles tenderiam a negligenciar um aspecto importante, a saber, "o caráter mundano da atividade receptiva, ou seja, o fato de que a recepção dos produtos da mídia é uma rotina, uma prática que muitos indivíduos integram como parte de suas vidas cotidianas" (op. cit.:41). 
sentido da reprodução dos lugares sociais e culturais e, também, dos modos de resistência mobilizados neste processo, mais especificamente, os modos de apropriação e de resposta das classes subalternas.

\title{
2. SOBRE A PESQUISA E SOBRE OS TELESPECTADORES DA TELENOVELA BRASILEIRA
}

Para que possamos dar visibilidade aos pressupostos teóricos que norteiam este trabalho, escolhemos iniciar esta segunda parte pela apresentação da metodologia da pesquisa cujos dados iremos analisar. Esta metodologia pressupõe que os sujeitos pertencentes ao que Martín-Barbero chama de classes subalternas "assumem, porque não lhes resta alternativa, uma indústria vulgar e pedestre, e certamente a transformam em complacência e degradação, mas também em identidade regozijante e combativa" (op.cit.:281). Para o autor, o estudo dos usos nos obriga a deslocar nosso interesse para o lugar onde os sentidos das "formas simbólicas mediadas" são produzidos: para os movimentos sociais e de um modo especial para aqueles que partem do bairro" (op.cit::281). O autor justifica esta opção metodológica por acreditar que nestes lugares "se vai forjando uma cultura específica dos setores populares", a saber,

\begin{abstract}
uma cultura política que já não é a dos trabalhadores, aquela visão de mundo frontalmente questionadora dos anarquistas e dos socialistas e sim uma outra mais reformista, que via a sociedade como algo que poderia ser aperfeiçoado, uma sociedade que, sem ser radicalmente diferente da existente, poderia chegar a ser bem mais organizada, mais justa. Visão configurada a partir da imagem (e da experiência) de mobilidade social oferecida pela sociedade e a partir da percepção de que a sociedade e Estado tinham atingido um incontestável grau de solidez. (op.cit.:282)
\end{abstract}

Assim, para o autor, o bairro "é o grande mediador entre o universo privado da casa e o mundo público da cidade, um espaço que se estrutura com base em certos tipos de sociabilidade e, em última análise, de comunicação: entre parentes e entre vizinhos" (op.cit:286). Um outro mediador importante para Martín-Barbero, principalmente quando se procura compreender a recepção televisiva, é o grupo familiar. Para o autor, a televisão da América Latina ainda tem a família como unidade básica de audiência. Isto ocorre porque para a maioria das pessoas ela representa a situação primordial de reconhecimento. Sobre este tópico, falaremos mais adiante.

Os sujeitos pesquisados que forneceram o material para esta reflexão são moradores de um bairro periférico da cidade de Indaiatuba, interior do estado de São Paulo. A pesquisa ${ }^{9}$ desenvolvida por Nogueira (2003) tinha como principal objetivo compreender as diferentes formas de interação dos sujeitos com a narrativa televisiva.

${ }^{9}$ A pesquisa de Iniciação Científica financiada pelo CNPq, realizada por Cássia Michela Alves Nogueira, intitulada "Narrativa e sociedade: descrevendo as diferentes recepções da telenovela brasileira", foi desenvolvida no período de agosto de 2002 a julho de 2003, no Instituto de Estudos da Linguagem da Universidade Estadual de Campinas, sob orientação da Profa. Dra. Anna Christina Bentes. 
Inicialmente, a pesquisadora procurou conversar com famílias que conhece há anos, ou seja, com grupos familiares da comunidade em que mora no bairro acima citado.

Em seu relatório de pesquisa, Nogueira (2003) ressalta algumas das dificuldades que enfrentou em relação à participação dos sujeitos na pesquisa. Apesar de ser conhecida de muitas das famílias que selecionou para fazer o primeiro contato, a maioria dos grupos familiares, depois de uma explicação sobre os objetivos e sobre a metodologia da pesquisa, desistiam de participar. Foi uma moradora do bairro, vizinha e amiga da família da pesquisadora que a apresentou aos núcleos familiares que aceitaram ser entrevistados e compartilhar com a pesquisadora os momentos em que assistiam às telenovelas. Martín-Barbero chama a atenção para este tipo de liderança exercido pelas mulheres nos bairros: o de recriação de uma sociabilidade primordial, o de promoção da união entre as tramas sociais e as afetivas, as problemáticas e as alternativas, a dor e a esperança" (op.cit:285).

A pesquisadora entrevistou e observou, durante seis meses, duas vezes por semana, a prática cotidiana de assistir televisão de quatro núcleos familiares, com renda mensal de até seis salários mínimos. A constituição dos núcleos familiares e a caracterização social dos elementos que compõem estes núcleos encontram-se sucintamente descritos nos quadros abaixo:

NÚCLEO FAMILAR A

\begin{tabular}{|c|c|c|c|c|c|c|}
\hline NOME & SEXO & IDADE & LUGAR DE ORIGEM & $\begin{array}{l}\text { TEMPO QUE } \\
\text { DEIXOU O } \\
\text { LUGAR DE } \\
\text { ORIGEM } \\
\end{array}$ & PROFISSÃO & $\begin{array}{l}\text { ESCOLA- } \\
\text { RIDADE }\end{array}$ \\
\hline $\mathrm{JB}$ & MASCULINO & 46 ANOS & GARANHUNS-PE & 43 ANOS & $\begin{array}{l}\text { INFORMAL - } \\
\text { CONST.CIVIL }\end{array}$ & $\begin{array}{l}\text { ENS. FUND. } \\
\text { INCOMPLE- } \\
\text { TO }\end{array}$ \\
\hline $\mathrm{CB}$ & FEMININO & 33 ANOS & IVATÉ-PR & 13 ANOS & DOMÉSTICA & $\begin{array}{l}\text { ENS. FUND. } \\
\text { INCOMPLE- } \\
\text { TO }\end{array}$ \\
\hline $\mathrm{AB}$ & FEMININO & 18 ANOS & IVATÉ-PR & 13 ANOS & - & $\begin{array}{l}\text { ENS. MÉDIO } \\
\text { COMPLETO }\end{array}$ \\
\hline LB & FEMININO & 13 ANOS & INDAIATUBA- SP & - & ESTUDANTE & - \\
\hline RB & MASCULINO & 07 ANOS & INDAIATUBA - SP & - & ESTUDANTE & - \\
\hline
\end{tabular}

NÚCLEO FAMILAR B

\begin{tabular}{|l|l|l|l|l|l|l|}
\hline NOME & SEXO & IDADE & LUGAR DE ORIGEM & $\begin{array}{l}\text { TEMPO QUE } \\
\text { DEIXOU O } \\
\text { LUGAR DE } \\
\text { ORIGEM }\end{array}$ & PROFISS ÃO & $\begin{array}{l}\text { ESCOLARI- } \\
\text { DADE }\end{array}$ \\
\hline ED & MASCULINO & 58 ANOS & CARANGOLAS-MG & 39 ANOS & $\begin{array}{l}\text { AJUDANTE } \\
\text { GERAL }\end{array}$ & $\begin{array}{l}\text { NÃO } \\
\text { ALFABETI- } \\
\text { ZADO }\end{array}$ \\
\hline ND & FEMININO & 43 ANOS & MANGA -MG & 31 ANOS & $\begin{array}{l}\text { COSTUREI- } \\
\text { RA }\end{array}$ & $\begin{array}{l}\text { ENS. FUND. } \\
\text { INCOMPLE- } \\
\text { TO }\end{array}$ \\
\hline
\end{tabular}




\begin{tabular}{|l|l|l|l|l|l|l|}
\hline DD & FEMININO & 18 ANOS & TOLEDO-PR & 13 ANOS & $\begin{array}{l}\text { AUXILIAR } \\
\text { DE CAIXA } \\
\text { DE } \\
\text { SUPERMER- } \\
\text { CADO }\end{array}$ & $\begin{array}{l}\text { ENS. MÉDIO } \\
\text { INCOMPLE- } \\
\text { TO }\end{array}$ \\
\hline MD & MASCULINO & 16 ANOS & TOLEDO-PR & 13 ANOS & ESTUDANTE & - \\
\hline WD & MASCULINO & 14 ANOS & TOLEDO-PR & 13 ANOS & ESTUDANTE & - \\
\hline
\end{tabular}

NÚCLEO FAMILIAR C

\begin{tabular}{|l|l|l|l|l|l|l|}
\hline NOME & SEXO & IDADE & LUGAR DE ORIGEM & $\begin{array}{l}\text { TEMPO QUE } \\
\text { DEIXOU O } \\
\text { LUGAR DE } \\
\text { ORIGEM }\end{array}$ & PROFISSÃO & $\begin{array}{l}\text { ESCOLARI- } \\
\text { DADE }\end{array}$ \\
\hline JÁ & MASCULINO & 39 ANOS & $\begin{array}{l}\text { PANELA DE } \\
\text { MIRANDA- PE }\end{array}$ & 32 ANOS & $\begin{array}{l}\text { OPERADOR } \\
\text { DE } \\
\text { MÁQUINAS }\end{array}$ & $\begin{array}{l}\text { ENS. FUND. } \\
\text { INCOMPLE- } \\
\text { TO }\end{array}$ \\
\hline QA & FEMININO & 33 ANOS & DOURADINA-PR & 10 ANOS & DOMÉSTICA & $\begin{array}{l}\text { ENS. FUND. } \\
\text { INCOMPLE- } \\
\text { TO }\end{array}$ \\
\hline
\end{tabular}

NÚCLEO FAMILIAR D

\begin{tabular}{|l|l|l|l|l|l|l|}
\hline NOME & SEXO & IDADE & LUGAR DE ORIGEM & $\begin{array}{l}\text { TEMPO QUE } \\
\text { DEIXOU O } \\
\text { LUGAR DE } \\
\text { ORIGEM }\end{array}$ & PROFISSÃO & $\begin{array}{l}\text { ESCOLARI- } \\
\text { DADE }\end{array}$ \\
\hline JC & MASCULINO & 27 ANOS & MARAVILHA- AL & 10 ANOS & $\begin{array}{l}\text { AJUDANTE } \\
\text { DE SOLDA }\end{array}$ & $\begin{array}{l}\text { ENS. FUND. } \\
\text { INCOMPLE- } \\
\text { TO }\end{array}$ \\
\hline SR & FEMININO & 28 ANOS & MARANHÃO & - & - & $\begin{array}{l}\text { ENS. FUND. } \\
\text { INCOMPLE- } \\
\text { TO }\end{array}$ \\
\hline
\end{tabular}

Os quadros acima permitem entrever algumas características do grupo entrevistado e observado: em primeiro lugar, os pais e mães de família são oriundos de outras regiões do país, principalmente do estado do Paraná, Minas Gerais e de estados do nordeste brasileiro (Maranhão, Alagoas e Pernambuco). Em sua grande maioria, deixaram seus lugares de origem há mais de 10 anos. Os núcleos familiares A, B e C possuem casa própria. Apenas o casal que compõe o núcleo familiar $\mathrm{C}$ possui carro. As informações fornecidas aqui são importantes na medida em que deverá ser discutido mais adiante quais demandas este grupo social, com as características acima descritas, elabora em relação à televisão, mais especificamente, em relação à telenovela. A metodologia de pesquisa encontra-se baseada na perspectiva etnográfica postulada por Geertz (1999) e por Clifford (2002). A pesquisadora não só entrevistou, como também observou as práticas dos grupos familiares acima mencionados em relação às telenovelas que estavam sendo exibidas naquele período. No período em que a pesquisa foi desenvolvida, algumas novelas estavam terminando e outras começando. Assim, a pesquisadora acompanhou as práticas dos espectadores assitindo às seguintes novelas que estavam sendo exibidas pela Rede Globo de Televisão:"Malhação”(17h), "Sabor da 
Paixão" (18h), "O Beijo do Vampiro" (19h), "Esperança" (20h), "Agora é que são elas" (18h), "Kubanacan" (19h) e "Mulheres Apaixonadas".

\section{SOBRE O GÊNERO TELENOVELA}

Antes de iniciarmos uma descrição um pouco mais detalhada das características composicionais da telenovela, é importante assinalar que nossa concepção de gêneros do discurso pode ser aproximada de uma das formulações construídas por Marcuscchi (2002), a saber, aquela que os considera como "artefatos culturais".

Em consonância com o que dissemos anteriormente, a valorização do aspecto cultural na análise das práticas comunicativas significa considerar sempre e fundamentalmente a diversidade dos sujeitos e dos atos de leitura por eles produzidos. É neste sentido também que entendemos o fato de um gênero textual ser resultado de um trabalho coletivo histórico, ou seja, um trabalho que resulta do que Bakhtin (1977/1988) chama de interação do locutor e do interlocutor. Assim, a telenovela, o nosso "folhetim eletrônico" é um locus privilegiado de observação dessa interação entre autor e público, que pode ser qualificada nos termos de Martin-Barbero (2003), como uma "dialética entre escritura e leitura". Esta relação constitutiva entre o campo da produção e o campo da recepção do folhetim pode ser percebida pela caracterização feita pelo autor de suas características composicionais e da descrição do seu funcionamento na sociedade em que surgiu, a França de meados do século XIX.

O surgimento do folhetim implica, segundo Martín-Barbero, tanto um modo específico de produção escrita, que se encontra entre a escrita jornalística e a escrita ficcional, (marcado pela necessária periodicidade e pela pressão salarial a que é submetido o escritor), como um novo modo de leitura, que rompe com o isolamento e a distância do escritor e o situa no espaço de uma interpelação permanente por parte dos leitores. Sendo assim, o processo de incorporação do "mundo do leitor" à escritura do folhetim pode, ainda segundo o autor, ser percebido a partir dos traços que deixa no texto. Para os interesses deste artigo, três são os dispositivos através dos quais se pode perceber a inscrição dos receptores no processo de produção do folhetim: o dispositivo da fragmentação da leitura, o da sedução e o da produção do reconhecimento. $\mathrm{Na}$ próxima seção, trataremos de explicitar o modo como dois destes dispositivos encontram-se também presentes na recepção da telenovela brasileira.

Em um outro nível de análise, acreditamos que se faz necessário também compreender a telenovela (que é um folhetim em uma versão midiática e latinoamericana) como um gênero que compartilha muitas de suas características com a literatura dialógica (Bakhtin, 1988) em que autor, espectador e personagens trocam de posição constantemente. A este respeito, Martín-Barbero (2003) afirma que o intercâmbio de posições enunciativas provoca uma confusão entre narrativa e vida:

Não no sentido de transferir para a narrativa as coisas da vida, pois não é a representação dos fatos concretos e particulares o que produz o sentido de realidade na ficção, mas uma certa generalidade que visa ambos os lados e dá consistência tanto aos fatos particulares do real quanto ao mundo fictício. (op.cit:320) 
Além disso, devemos sempre lembrar que tanto o campo da produção como o campo da recepção de um determinado gênero (e/ou de um conjunto deles) encontra-se situado em uma determinada "esfera de atividades" (Bakhtin,1979/1992), ou ainda no interior de um determinado "domínio discursivo" (Marcuschi, 2002). Na introdução, mencionamos rapidamente algumas características do meio de comunicação, a televisão, no interior do qual o gênero telenovela é produzido. É também importante lembrar que a televisão é considerada um meio hegemônico em função do fato de realizar-se na unificação da demanda, ou seja, por apresentar uma tendência à constituição de um só público, no qual sejam absorvidas as diferenças (Martín-Barbero, 2003). No entanto, as ações responsivas dos sujeitos são sim diferenciadas e, em muitas formulações, dependem dos diversos tipos de competência ${ }^{10}$ desenvolvidos pelos interlocutores. Neste trabalho, assumiremos que os sujeitos, ao responderem ativamente às mensagens que lhe são dirigidas, mobilizam competências de natureza multifacetada, tais como as formuladas por Koch (2002): a competência sociocomunicativa, a competência textual e a competência metatextual.

É também a partir da observação das ações responsivas dos sujeitos que se podem observar tanto as formas pelas quais ocorrem (i) as reapropriações dos conteúdos simbólicos previamente formulados e (ii) a reapropriação de uma (meta)linguagem que permita uma outra enunciação, esta agora produzida a partir dos interesses próprios e das próprias regras dos interlocutores. Na próxima seção, analisaremos estes dois aspectos da recepção da telenovela com base na pesquisa desenvolvida por Nogueira (2003).

No intuito de tentar compreender o tipo de "esfera de atividades" no interior do qual o gênero aqui analisado é produzido, consideremos as postulações de Thompson (2002), para quem os meios de comunicação de massa podem ser concebidos como um campo de "produção institucionalizada e difusão generalizada de bens simbólicos através da fixação e transmissão de informação ou conteúdo simbólico", definição esta que pode ser desdobrada em cinco características: (i) o envolvimento de certos meios técnicos e institucionais de produção e difusão de formas simbólicas; (ii) a mercantilização das formas simbólicas no sentido de que os objetos produzidos pelas instituições da mídia passam por um processo de valorização econômica; (iii) a dissociação estrutural entre a produção das formas simbólicas e a sua recepção; (iv) a extensão da disponibilidade das formas simbólicas no tempo e no espaço, ou seja, as "mensagens mediadas" se tornam disponíveis em contextos os mais remotos e distantes dos contextos em que as mensagens foram originalmente produzidas; (v) a disponibilidade a uma pluralidade de receptores, o que necessariamente, segundo o autor, provoca um impacto muito grande na relação entre o público e o privado.

A breve descrição do contexto institucional no qual é produzido o gênero em questão, a saber: no interior de uma relação profundamente assimétrica entre produtores e receptores, nos permite afirmar que a recepção da telenovela (e de alguns outros produtos da mídia televisiva) exerce (ao contrário do que Thompson (2002) afirma

\footnotetext{
${ }^{10}$ A respeito da importância desta noção no campo da sociologia, ver Morato \& Bentes (2002).
} 
sobre a circunscrita possibilidade de intervenção ou de contribuição dos receptores em relação aos produtos da indústria cultural) um impacto imediato e decisivo sobre sua produção.

Por fim, é importante chamar a atenção para o fato de que a telenovela é um gênero construído a partir da manipulação de recursos lingüísticos e discursivos (que são primeiramente produzidos na modalidade escrita) e recursos audio-visuais, o que nos obriga a procurar produzir análises não só sobre o embricamento destas linguagens, mas principalmente sobre a maneira como os sujeitos nas sociedades modernas demonstram possuir um conhecimento convencionado (Bhatia, 1997) em relação a gêneros não só fundamentalmente "orais" ou "escritos", mas também em relação aos gêneros que são constituídos de maneira definitiva por uma diversidade de linguagens. Este tipo de abordagem nos ajudará a compreender melhor o papel desempenhado pela linguagem natural na elaboração e compreensão das formas simbólicas mais presentes, mais atualmente sedutoras e, de muitas maneiras, mais acessadas pelos sujeitos nas sociedades contemporâneas.

\section{SOBRE A RECEPÇÃO ${ }^{11}$ DA TELENOVELA}

O primeiro aspecto da recepção da telenovela que abordaremos nesta seção será o fato de que "assistir novela" é uma atividade de rotina, no sentido de que é parte integrante das atividades da vida diária. Em outras palavras, a recepção deste e de outros produtos da indústria cultural se sobrepõe a outras atividades e uma parte da importância que os tipos particulares de recepção desempenham na vida dos indivíduos resulta da maneira como eles os relacionam a outros aspectos de suas vidas.

Os dados da pesquisa desenvolvida por Nogueira (2003) junto a grupos familiares com renda de até seis salários mínimos de um bairro periférico da cidade de Indaiatuba, interior de São Paulo, mostram que, de fato, as atividades de recepção dos produtos midiáticos apresentam um caráter rotineiro, mas este caráter parece estar inevitavelmente ligado ao fato de os sujeitos encontrarem-se impossibilitados de desenvolver outras "rotinas" já que, em seu "tempo livre", não dispõem de outras possibilidades de lazer e diversão. Vejamos alguns exemplos de como os sujeitos entrevistados parecem não conseguir "escapar" da única alternativa que lhes resta para preencher o tempo antes ou depois do trabalho ou da escola:

(1) JB: (...) eu ligo a televisão porque estou aí à toa, né?

(2) $\quad \mathrm{AB}: \quad$ (...) porque eu estudo à noite e a maioria (das telenovelas) passa à noite então eu não tenho tempo aí eu assisto mesmo a Malhação porque dá tempo durante o dia e as outras às vezes quando tem um tempinho só...

11 O material que será analisado nesta seção faz parte do conjunto de entrevistas que foram conduzidas por Nogueira (2003) durante a primeira fase de sua pesquisa de campo. 
ED: a novela para mim é uma coisa que a gente assiste, né? que é uma hora que eu não tenho o que fazer nessa hora (...) então a novela para mim é mais um esporte que é uma hora que eu não tenho o que fazer... eu chego cansado do trabalho né? tomo meu banho... eu não tenho aonde ir ...

No entanto, para ND, "assistir novela" é uma atividade que lhe possibilita construir um distanciamento de sua vida cotidiana, ou seja, por um momento, ela pode colocar-se acima de seu contexto mais imediato e "perder-se em outro mundo". Para Thompson (2002:92), é exatamente o fato de os sujeitos receberem materiais que são produzidos em contextos distantes que lhes possibilita construir o distanciamento de que fala a entrevistada:

(4) ND: (...) ... então, eu já gosto de assistir... pelo menos eu estou tirando a tensão que eu já... que a gente já chega do trabalho com aquela tensão então a novela a gente senta pra ver ela ... é uma coisa que parece que muda aí começa ... a passar alguma coisa engraçada ... eu começo a dar risada os meninos morrem de dar risada de mim sobre isso né? Diz que lá da rua escuta eu dar risada e às vezes é uma alguma coisa engraçada que passa né?...

É claro que a atitude de ND pode ser analisada como uma forma de alienação social, mas, se insistirmos em um posicionamento teórico que compreende o espectador como um produtor ativo de sentidos e se nos apropriarmos de uma metodologia que nos permita observar e compreender melhor os sujeitos de nossas pesquisas, veremos que ND é um tipo de espectador muito engajado ${ }^{12}$ na atividade "assistir novela" (ela afirma em outro trecho da entrevista "eu gosto de assistir as novelas porque eu gosto mesmo de assistir novela, né?") e que demonstra uma certa maestria na forma de percepção do gênero.

Esta maestria pode ser observada se considerarmos o que Martín-Barbero propõe como o dispositivo do reconhecimento produzido pelo folhetim literário e pelo nosso atual folhetim eletrônico. Para Martín-Barbero, o reconhecimento não deve ser concebido apenas em termos negativos, como uma mera operação de redundância, mas principalmente como uma forma de interpelação: "Todos se fazem e se refazem na trama simbólica das interpelações, dos reconhecimentos. Todo sujeito está sujeito a outro e é ao mesmo tempo sujeito para alguém" (op.cit.:316). Há, segundo o autor, "uma luta por se fazer reconhecer". Assim, ND, ao discorrer sobre as novelas de que gosta, revela exatamente esta possibilidade de se identificar, reconhecer nos tipos de sofrimento humano (a perda de um pai, de um filho, o abandono dos filhos por parte dos pais) apresentados nas/pelas telenovelas, o que poderia constituir-se em um motivo para o exercício da solidariedade que, por sua vez, é responsável pelo que MartínBarbero chama de "formas de sociabilidade primordial". É neste espaço que, ainda segundo o autor, pode ser encontrada a marca da hegemonia, já que discursos e imagens são familiarizados, tornados próximos, dando forma a uma cotidianidade

12 Nogueira (2003) propõe uma classificação inicial e provisória dos espectadores a partir da observação sistemática das práticas dos sujeitos em relação à mídia televisiva, a saber: os espectadores engajados, os espectadores esporadicamente engajados e os espectadores não engajados. 
familiar que é apresentada como um espaço para as formas de relação primordial anteriormente citadas.

(5) ND: eu gosto de várias coisas que passa... porque ...uma pessoa que roubou a terra do outro né? e agora não quer pagar o que pertence àquela família que é proprietário da terra né? eu também me emocionei muito com a morte do Miguel, né? então foi um passagem muito triste

ENT: e porque a senhora se emocionou com esta parte?

ND: porque eu acho que aquilo que passou é a vida real que a gente vive de perder um pai de perder um marido de perder um filho né? eu acho que é uma passagem muito triste então é o que eu fiquei muito emocionada... eu chorei de ver o desespero deles né ... então eu acabei chorando também

(...) é isso também tem muitos de pais que abandona os filhos ... mulher e filhos né ... tudo e vai ter outra vida...

Uma outra maestria em relação ao gênero pode ser observada na forma como os sujeitos produzem resumos sobre o gênero em questão. No exemplo abaixo, ND constrói uma proposição geral sobre o tema principal de uma das telenovelas que acompanha. Além disso, a entrevistada ainda imediatamente articula a proposição geral a uma apreciação que, segundo Bakhtin (1977/1988), é responsável pela construção da significação objetiva. Uma outra entrevistada, CB, também demonstra a mesma habilidade que ND, articulando necessariamente a significação objetiva por ela produzida com a apreciação que faz do tema:

(6) ENT: e quais dessas novelas que estão passando agora que a senhora costuma assistir?

ND: mais? mais é o Sabor da Paixão né? e o Beijo do Vampiro

ENT: de que falam essas novelas? qual a história delas?

ND: olha o Beijo do Vampiro fala de um mito de uma lenda mas eu acho que vampiro não existe se existiu foi no século passado né? se existiu ... não existe... século passado não que no nosso século não teve né? é no outro século agora... eu gosto assim porque é uma coisa que fala... que tem o bem e o mal né? então tem o bem para combater o mal ... eu acho isso muito bonito ... eu acho bonito as passagens que passa...

(7) ENT: e do que é que trata essa novela? qual é a história dela?

CB: essa história aí é dos italianos né? da Itália lá ((risos)) então eu achei interessante por causa disso né? então isso que eu gosto de assistir quando eu tenho tempo eu assisto

Ao responder ao questionamento feito, ND ainda mobiliza um conhecimento sobre outros gêneros, relacionando-os com os temas gerais da telenovela e nomeandoos: "fala de um mito, de uma lenda". Este trecho é ainda revelador de um conhecimento convencionado por parte de ND de uma espécie de matriz cultural, ou seja, ND situa a telenovela em questão no interior de um determinado conjunto de gêneros que se encontram relacionados entre si em função do fato de produzirem, em termos de conteúdos simbólicos, uma verticalização de toda a experiência: as narrações deste tipo separam taxativamente o bem e o mal, extinguindo a possibilidade de ambigüidades e exigindo uma tomada de posição por parte do leitor/ouvinte/espectador (MartínBarbero, 2003). Não é à toa que ND relaciona a telenovela "O Beijo do Vampiro" com mitos e lendas. Ela os reconhece como pertencendo ao domínio do maravilhoso.

No entanto, o conhecimento convencionado sobre a estruturação do gênero não é homogêneo mesmo no interior do mesmo grupo social. Vejamos os exemplos abaixo: 
(8) ENT: de que falam essas novelas? qual é a história delas?

QA: a... a história dela é meio complicada né?

ENT: do que elas tratam? qual a história que elas contam?

QA: ((risos)) agora fica difícil ((risos))

(9) ENT: e assim... do que falam essas novelas?

DD: o Beijo do Vampiro fala de vampiros e já a Esperança fala um pouquinho da nossa história que aconteceu ... conta um pouco da época do café ... isso também é uma forma de pegar um pouco da cultura brasileira dos imigrantes italianos como os italianos os espanhóis e poloneses que vieram para o Brasil procurar uma chance melhor de sobreviver.

(10) ENT: e essa que o senhor assiste mais do que ela fala? qual a história dela?

JB: essa daí fala muito dos outros países né? ... é uma novela dos outros países né? com muita gente dos outros países né? mas é aqui dentro do Brasil né? essa uma né? que é essa... os italianos ... como é o outro?... judeu lá ...essas pessoas

O primeiro trecho mostra que a entrevistada não fala sobre o tema geral da novela. No entanto, antes de emitirmos qualquer julgamento sobre as diferentes formas de expressar o conhecimento convencionado sobre o gênero em questão, é importante lembrar que uma das características do gênero é exatamente a fragmentação da narrativa em episódios e capítulos.

A telenovela é um dos gêneros que menos se presta à elaboração de resumos de caráter geral, já que sua constituição mesma é dividida em vários "núcleos" que são relacionados ente si e que são constituídos por personagens que estabelecem relações internas ao núcleo e relações com os outros personagens dos outros núcleos, o que forma uma intricada rede temática. Sem falar, é claro, na fragmentação da trama ao longo de meses e meses, dia após dia. É em função desses diversos níveis de fragmentação que os sujeitos, quando perguntados sobre o tema geral da novela, ou constroem uma proposição geral do tipo "é a história aí dos italianos", "fala de vampiros", "fala muito dos outros países" (como no exemplo (9)) etc. ou acabam por esquivar-se da pergunta. Em ambos os casos, o que conseguimos perceber é que a aparente dificuldade dos sujeitos em produzir um resumo que represente a variedade de personagens e tramas presentes neste gênero narrativo expressa uma forma de compreensão da própria fragmentação característica do gênero em questão.

No interior do grupo social pesquisado, ocorrem, por parte dos sujeitos, diferentes formas de (re) apropriação tanto do conteúdo simbólico como da linguagem que lhes permite enunciar o que enunciam. O exemplo (8) é ilustrativo disso: a resposta dada à entrevistadora revela que a entrevistada elabora o resumo requisitado, chamando a atenção para a principal característica temática da novela das oito em questão: o seu caráter histórico.

O conhecimento convencionado sobre o gênero, que podemos denominar competência metagenérica, revela um tipo de inscrição ativa no domínio discursivo específico, o que implica a mobilização de uma linguagem que permita ao sujeito (i) o reconhecimento dos dispositivos característicos do gênero, (ii) a reelaboração dos conteúdos simbólicos produzidos em um contexto bem distante do contexto de recepção, (iii) o estabelecimento de relações com outros gêneros elou outras práticas 
sociais que colaborem para a reapropriação dos sentidos produzidos pelo/no gênero por parte dos interlocutores. Vejamos como DD compara a telenovela em questão com outros gêneros midiáticos e propõe uma outra configuração que teria como objetivo chamar mais ainda a atenção para o caráter histórico da trama:

(11) ENT: e o que você acha que é legal e o que você acha que falta?

DD: falta um pouquinho mais de ... de eles pegarem mais um pouco de história... mais a história do Brasil ... isso é o que falta... porque eu acho que seria legal também eles colocarem mais cenas dos filmes antigos que tem falado do Brasil como os telejornais que passavam em cinemas antes ... igual a gente está vendo em aula de história a gente está vendo a época de Getúlio Vargas para mim é interessante porque passou ... na era Getulista passou ... MMDC que foram quatro estudantes mortos nessa época dessa novela ...Miragaia Drausio e Camargo e o Martins que deram a sigla que teve a revolução brasileira e essa novela Esperança contou um pouco dessa revolução.

É interessante perceber como DD propõe uma maior inserção de outras linguagens no interior da telenovela ("cenas de filmes antigos"), o que mostra que ela possui uma demanda diferenciada em relação ao gênero em questão: a de que a novela se apresente como uma fonte mais precisa de informação histórica. Isto é tão presente que a entrevistada faz uma comparação entre a forma de apresentação de fatos históricos feitos pela/na telenovela e a aula de história. Pode-se dizer que DD parece estar fazendo uma demanda escolar desse gênero, ou seja, que ele apresente também uma função educativa. Além disso, a entrevistada, ao fazer referência a outros gêneros midiáticos (telejornal, filmes antigos), indica que a reelaboração dos conteúdos simbólicos pressupõe a comparação com outros gêneros produzidos no interior daquele domínio discursivo ou ainda com gêneros relacionados às esferas de atividades dos interlocutores. O conhecimento convencionado de DD sobre o gênero - sua competência metagenérica - provavelmente resulta de sua inserção social diferenciada: ela é mais jovem, mais escolarizada e já trabalha. No entanto, esta hipótese precisaria ser mais investigada.

Os exemplos abaixo são ilustrativos de como sujeitos pertencentes ao mesmo grupo social podem apresentar demandas bastante diferenciadas em relação a uma mesma telenovela, "O Beijo do Vampiro":

(12) ED: eu acho bonita né? a novela em si né? mas acho que essas coisas não existe né? e a gente acha por causa do conteúdo né?... igual vampiro... essas coisas não existem né? ela tem umas passagens muito bonitas ... eu acho bonito aquilo lá né?

ENT: mas... o que o senhor acha bonito realmente lá... nessa ... nessa

ED: as TRANS-FOR-MA-ÇÕES ((risos))

ENT: o senhor gosta das transformações?

ED: né? o que está ali de repente o cara vira um cachorrão né? vira um animal né? ((risos)) daí daquilo dali ... eu fico assim pensando "como é que pode fazer essas transformações tão rápidas né? ,, esses poderes que o cara está aqui e de repente desaparece ne'? então essas coisas eu acho interessante, né?

(13) ENT: e porque o senhor não gosta muito dessa?

JB: $\quad$ eu não acho fundação nela não ... não acho assim uma coisa certa não ... a todos aqueles caras virando vampiro lá para mim eu acho que é ... não gosto muito eu não... eu acho que é a novela mais ruim que está passando agora. 
A fala de ED sobre a novela "O Beijo do Vampiro" mostra, em primeiro lugar, que a recepção do espectador da mídia televisiva, mais especificamente da telenovela, pode revelar uma apropriação singular do gênero. O exemplo nos mostra que ED não se interessa apenas pelos conteúdos simbólicos veiculados nas/pelas telenovelas, mas fundamentalmente pelos recursos técnicos necessariamente mobilizados para a produção do gênero em questão. É interessante assinalar que ED pode ser classificado como um espectador esporadicamente engajado (Nogueira, 2003) em relação ao gênero (para ele, a novela é "uma coisa que a gente assiste, né?"). Por exemplo, em um outro momento da entrevista, ele afirma que gosta mesmo é do Jornal Nacional, que se pudesse "não perdia um dia":

(14) ED: (...) então o jornal se a gente acompanhar ele todo dia você está atualizado com os acontecimentos do nosso Brasil ou até do mundo inteiro né ... igual ontem passando no Jornal Nacional que o:: que o Estados Unidos estão querendo né dominar o Iraque ... tudo por quê? por causa do petróleo lá... mostrou um cara furando no chão lá com uma rodinha manual extraindo petróleo ... saindo pela bica de petróleo ... então eles querem dominar o país por isso para dominar o mundo inteiro ...

É importante trazer este trecho de uma fala de ED que revela uma reflexão crítica sobre os conteúdos simbólicos produzidos não pela narração, mas pela informação, nos termos de Benjamim (1994), porque acreditamos que as diversas competências metagenéricas de um determinado sujeito não estão desvinculadas e porque acreditamos que o entrecruzamento destas diversas competências é um dos fatores responsáveis pelas formas como os sujeitos se apropriam dos diversos gêneros e de cada um deles em particular. Assim, a singularidade da recepção de ED em relação à telenovela (com sua atenção voltada mais para a linguagem televisiva propriamente dita do que para os conteúdos simbólicos articulados na/pela narrativa) parece estar relacionada ao fato de ele ser um sujeito que faz um uso "tático" dos produtos da mídia televisiva. De qualquer maneira, nossas análises aqui carecem de ainda mais observação e participação das/nas práticas cotidianas dos sujeitos para que possamos de fato produzir "descrições densas" em que medida as histórias de vida e o perfil social (escolaridade, idade, sexo, classe social) dos espectadores constituem e atravessam a recepção dos produtos midiáticos.

Por último, comparando o exemplo (11) com o exemplo (12), percebemos que JB, ao contrário de $\mathrm{ED}$, focaliza os conteúdos simbólicos produzidos (e não os recursos técnicos) na/pela telenovela e os rejeita ("eu não acho uma coisa certa"). Esta atitude de rejeição ou de resistência em relação a determinados conteúdos simbólicos mostra que a recepção ${ }^{14}$ do gênero possibilita uma forma de réplica aos discursos hegemônicos

${ }^{13}$ A respeito da contribuição da abordagem etnográfica (que deve produzir, no dizer de Clifford Geertz, "descrições densas") para o campo da sociolingüística, ver Bentes (2003).

14 "No processo de recepção, os indivíduos usam as formas simbólicas para suas próprias finalidades, em maneiras extremamente variadas e relativamente ocultadas, uma vez que estas práticas não estão circunscritas a lugares particulares. Enquanto a produção 'fixa' o conteúdo simbólico em substratos materiais, a recepção o 'desprende' e o liberta para os estragos do tempo. Além disso, os usos que os 
produzidos no interior de um domínio discursivo profundamente assimétrico em sua estruturação.

\section{SOBRE O MUITO A SE FAZER....}

Ao longo deste trabalho nos propusemos a descrever algumas formas de recepção da telenovela brasileira, concebendo-a como um gênero do discurso. A primeira questão que fica em aberto para posteriores estudos é: será que esta categoria, da forma como tem sido pensada até agora, serve para a análise de gêneros que articulam de maneira definitiva a linguagem verbal a outros tipos de linguagem? Os estudiosos da comunicação tem apostado que sim e compreendem que os "gêneros" (sem adjetivação) possuem uma importante função de mediação entre a lógica do sistema produtivo e a lógica dos usos. Parece então que a demanda que está colocada para nós, estudiosos da linguagem, é a de procurar formular uma definição que nos permita ir além das caracterizações dos gêneros orais e/ou escritos e que englobe as sedutoras e sempre presentes formas simbólicas mais características das sociedades contemporâneas: as formas simbólicas midiáticas, especialmente as televisivas. Além disso, é ainda (e principalmente) de nossa responsabilidade analisar o papel desempenhado tanto pela linguagem oral como pela escrita nessa esfera específica de atividades.

Uma segunda questão importante que também fica em aberto é a do estatuto da recepção para a formulação de uma teoria sobre os gêneros do discurso. Em que medida os usos que os receptores fazem do gênero podem ser considerados como elementos constitutivos do próprio gênero? Neste trabalho, procuramos descrever as formas pelas quais as (re)apropriações operadas pelos sujeitos entrevistados refletem e revelam não só as caraterísticas dos gêneros, mas também a maneira como funcionam na sociedade e a forma como eles mesmos são constituídos como práticas sociais. A esse respeito, ainda vale a pena ressaltar que a observação e participação das/nas práticas cotidianas dos sujeitos foi extremamente importante para que tivéssemos uma idéia da complexidade e da diversidade da recepção da telenovela por parte dos sujeitos. Cada um deles, quando instado a refletir sobre suas ações responsivas, revela uma "faceta" do espectador e, ao se deixar mostrar, nos coloca questões a respeito de como compreender a recepção sem deixar de considerar os processos de subjetivação e os conflitos que dele decorrem.

Fica ainda em aberto a discussão sobre a maneira pela qual procuramos contextualizar tanto a produção dos gêneros como a sua recepção. Quais deveriam ser as maneiras de produzirmos "descrições densas", no dizer de Geertz (1999), das "esferas de atividades" em que os gêneros são produzidos e consumidos? Em que

receptores fazem das matérias simbólicas que lhes são oferecidas podem divergir consideravelmente (se é que houve) daqueles pensados ou queridos pelos produtores. Mesmo que os indivíduos tenham pequeno ou nenhum controle sobre os conteúdos das matérias simbólicas que lhe são oferecidas, eles os podem usar, trabalhar, reelaborar de maneiras totalmente alheias às intenções ou aos objetivos dos produtores". (Thompson, 2002:42). 
medida estas descrições poderiam nos levar a melhor compreender a natureza deste objeto, o gênero, que é, ao mesmo tempo, evidente e sutil?

Colocar um ponto final em qualquer trabalho é sempre difícil. Neste, especialmente, um pouco mais, já que as questões em aberto (as apontadas e as outras que virão) são numerosas e importantes. Esperamos, no entanto, que as análises produzidas até aqui e as perguntas presentes nessas considerações finais possam ser úteis para futuras reflexões.

\section{BIBLIOGRAFIA}

ANDRADE, R.M.B. de. (2002). "Telenovela e vida cotidiana". Comunicação \& Educação, São Paulo, (25): 28 a 35 , set.dez.

BAKHTIN, M. (1988). Marxismo e filosofia da linguagem. São Paulo: Editora Hucitec. (Edição original, 1929).

. (1992). Estética da criação verbal. São Paulo: Martins Fontes. (Edição original, 1979).

BENJAMIM, Walter. (1994). "O narrador: considerações sobre a obra de Nikolai Leskov". In: Obras escolhidas I - Magia e técnica, Arte e política: ensaios sobre a literatura e história da cultura. São Paulo: Editora Brasiliense, $7^{\mathrm{a}}$ edição.

BENTES, A.C. (2003). A abordagem etnográfica em pesquisa sociolingüística: implicações teóricas e analíticas para o campo. Comunicação apresentada no $51^{\circ}$ Seminário do GEL, Taubaté, São Paulo, 22 a $24 / 05 / 03$. (no prelo)

BHATIA, V.K. (1997). "Genre analysis today". Revue Belge de Philologie et d'Histoire. Bruxelles, 75:629652. [Tradução: Benedito Gomes Bezerra].

CANCLINI, N.G. (1997). Consumidores e cidadãos. Rio de Janeiro: Editora da UFRJ. (Edição original, 1995).

CERTEAU, M. (1996). de. A invenção do cotidiano - 1: artes de fazer. Rio de Janeiro: Vozes. (Edição original, 1994)

CLIFFORD, J. (2002). A experiência etnográfica: antropologia e literatura no século XX. Rio de Janeiro: Editora da UFRJ. (Edição original, 1994).

COSTA, S.R. "Entre o rural e o urbano: a recepção da telenovela em Serra da Saudade, MG". Revista Brasileira de Ciência da Comunicação. Vol. XXII, no.1, jan/jul.1999, p. 123-142.

GEERTZ, C. (1999). O saber local: novos ensaios em antropologia interpretativa. Rio de Janeiro: Vozes.

GOMES-SANTOS, S.N. (2003). Recontando histórias na escola: gêneros discursivos e produção da escrita. São Paulo: Martins Fontes.

HAMBURGER, E. (1998). "Vale Tudo e as consequiências não antecipadas da modernização". Imagens. nº 8, maio/agosto, p. 34-43.

JACKS, N. (1996). "Tempo e espaço e recepção". In: FAUSTO NETO, A. \& PINTO, M.J. (orgs.) $O$ indivíduo e as mídias. Rio de Janeiro: Diadorim.

KOCH, I.G.V. (2002). Desvendando os segredos do texto. São Paulo: Cortez. 
MACHADO, A. (1998). “Televisão: a questão do repertório”. Imagens. nº 8, maio/agosto, p. 09-19.

MARTÍN-BARBERO, J. (2003). Dos meios às mediações: comunicação, cultura e hegemonia. Rio de Janeiro: Editora da UFRJ. (Edição original, 1987)

MARCUSCHI, L.A. (2002). "Gêneros textuais: definição e funcionalidade”. In: Gêneros textuais e ensino. Rio de Janeiro: Editora Lucerna.

MORATO, E. \& BENTES, A.C. (2002). "Das intervenções de Bourdieu no campo da Lingüística: reflexões sobre competência e língua legítima”. Horizontes: Dossiê: Bourdieu, vol. 20, jan./dez. 2002. p.

NOGUEIRA, C.M. "Relatório de final de atividades do projeto 'Narrativa e sociedade: descrevendo as diferentes recepções da telenovela brasileira'”. Projeto de Iniciação Científica financiado pelo CNPq e desenvolvido no Instituto de Estudos da Linguagem da Universidade Estadual de Campinas, agosto de 2002 a julho de 2003.

RIO, V.C. "Processos de recepção de narrativas midiáticas: um estudo sociolingüístico da recepção do programa 'Brava gente"”. Projeto de Iniciação Científica financiado pela FAPESP e desenvolvido no Instituto de Estudos da Linguagem da Universidade Estadual de Campinas, iniciado em agosto de 2003.

ROMANO, M.C.J. (1996). "Análise da composição textual das telenovelas - percurso necessário para pensar o fenômeno da recepção". In: FAUSTO NETO, A. \& PINTO, M.J. (orgs.) O indivíduo e as mídias. Rio de Janeiro: Diadorim.

RONDELLI, E. (1998). "Realidade e ficção no discurso televisivo”. Imagens. nº 8, maio/agosto, p. 26-35.

RONSINI, V.M. (1996). "O que acontece aqui e lá no fim do mundo: como pensar esta relação nos estudos de recepção". In: FAUSTO NETO, A. \& PINTO, M.J. (orgs.) O indivíduo e as mídias. Rio de Janeiro: Diadorim.

THOMPSON, J.B. (2002). A mídia e a modernidade: uma teoria social da mídia. Rio de Janeiro: Vozes. (Edição original, 1995). 